
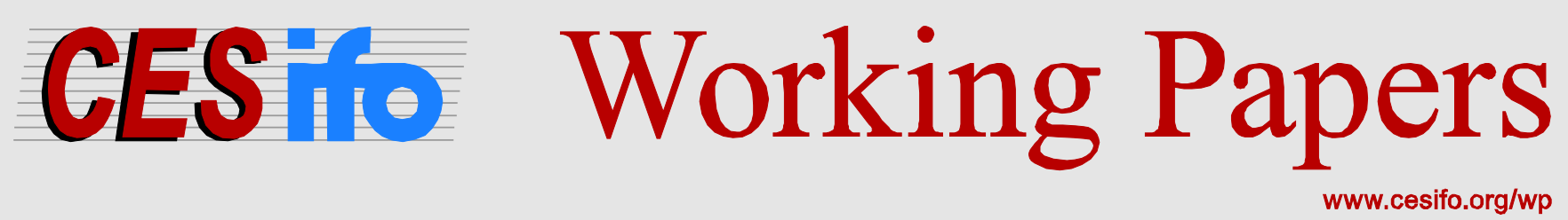

\title{
The Commitment Value of Prefunded Pensions
}

\author{
Jean-Denis Garon
}

\author{
CESIFO WORKING PAPER NO. 5658 \\ CATEGORY 1: PUBLIC FINANCE \\ DECEMBER 2015
}

An electronic version of the paper may be downloaded

- from the SSRN website:

- from the RePEc website:

- from the CESifo website:

www.SSRN.com

www.RePEc.org

www.CESifo-group.org/wp 


\title{
The Commitment Value of Prefunded Pensions
}

\begin{abstract}
This paper studies how prefunding public pensions can improve policy outcomes when shortsighted governments cannot commit. We focus on sustainable plans, where optimal nonlinear pensions are not reneged on by sequential governments. Prefunding pensions is a commitment mechanism. It implies lower contributions than does the second best policy, which reduces temptation to over-redistribute later and to misuse revealed private information. Prefunding may be preferable even if the population growth rate is higher than the rate of return on assets. Second best optimal policies are also more likely to be renegotiation proof under prefunding.
\end{abstract}

JEL-Codes: H550, H310.

Keywords: pensions, commitment, redistribution, prefunding.

\author{
Jean-Denis Garon \\ ESG-UQAM \\ C.P. 8888, Succ. \\ Centre-Ville Montréal \\ UC Canada H3C $3 P 8$ \\ garon.jean-denis@uqam.ca
}

December 4, 2015

The author thanks Robin Boadway, Sam Bucovetzky, Thorsten Koeppl, Sumon Majumdar, Tanguy Van Ypersele and Jan Zabojnik for their comments and suggestions. 


\section{Introduction}

Publicly managed pension plans are subjected to political risks (Diamond, 1994, 1996). Governments, even if they are benevolent, may be tempted to engage in excess redistribution across retirees using pension wealth. Because of this, some have argued that prefunding and privatizing public pensions could reduce political risks

Recent literature in dynamic optimal taxation, among which Farhi et al. (2012), has shown that commitment is especially relevant in non-linear optimal tax problems, in which the fiscal schedule must induce individuals to reveal private information about themselves. If the policy maker can improperly use revealed information and renege on its promises, the characteristics of the optimal policy may be significantly affected.

Farhi et al. (2012) show that governments who cannot commit should tax capital accumulation progressively. This has the effect of reducing income inequality in the optimum. Sequentially, governments thus have fewer incentives too misuse households' private information to over-redistribute. They study sustainable equilibria à la Chari and Kehoe (1990) that are perfect Bayesian and that can be sustained by a trigger-type reaction by the households following a governmental deviation.

In a simpler framework, we extend their analysis to show how the institutional structure of public pension, whether it is pre funded or unfunded, may help or harm pension policy outcomes when commitment is assumed away. We use a simple, overlapping generations model, with infinite repeated between governments and successive generations of individuals. An initial social planner who sets the generosity and the redistributiveness of a pension plan must ensure that successive short-sighted governments do not have an incentive to renege on the initial promises.

Our results formalize the idea that prefunding pensions may be used as a commitment mechanism. Under prefunding, the optimal response to a lack of commitment is to reduce 
aggregatae pension contributions to reduce next period's temptation. With unfunded plans, immediate temptation to over redistributes involves higher contributions than in the second best plan and much less inequality. We use numerical examples to show that optimal second best policies are more likely to be sustainable under prefunding. Due to its pre-commitment value, prefunding may be preferable to pay-as-you-go scheme even when population grows faster than the interest rate.

\section{Model}

In this overlapping generations version of Stiglitz (1982) where individuals live for two periods of equal duration. In the first half of their lives individuals supply labor, consume, are taxed and contribute to a public pension fund. In their second half they are retired and live off public pension benefits. The timing of retirement is exogenous and population grows at a fixed rate $\eta>0$. Thus, at each period $t=0,1, \ldots$ one generation of workers cohabits with a generation of retirees. Therefore, the constant ratio of workers to retirees is $1+\eta$. There is a constant proportion $n_{i}$ of type $i$ agents, where types are denoted by $i=1,2$. There is an underlying linear production technology according to which a type $i$ worker who supplies $\ell_{t}^{i}$ units of labor faces a hourly market wage rate $w_{i}$ with $w_{1}<w_{2}$. Gross incomes are defined as $y_{t}^{i} \equiv w_{i} \ell_{t}^{i}$. All individuals have identical, time separable utility functions:

$$
U\left(c_{t}^{i}, \ell_{t}^{i}, d_{t+1}^{i}\right)=u\left(c_{t}^{i}\right)-z\left(y_{t}^{i} / w_{i}\right)+\beta u\left(d_{t+1}^{i}\right)
$$

where $c_{t}^{i}, y_{t}^{i} / w_{i} \equiv \ell_{t}^{i}$ and $d_{t+1}^{i}$ are respectively the consumption level of a worker born at $t$, the worker's labor supply and the worker's consumption when old at $t+1$. Instantaneous consumption utility $u$ is strictly increasing, strictly concave and obey the limiting condition $u^{\prime}(0)=\infty$. The utility cost of supplying labor $z$ is strictly increasing and strictly convex with $z^{\prime}(0)=0$ and $z^{\prime \prime}(\ell)>0, \forall \ell$. The utility function satisfies the single-crossing condition since, the marginal cost of earning gross revenue satisfies $z^{\prime}(y) / w_{2}<z^{\prime}(y) / w_{1} \forall y$. 
A social planner ranks allocations $\phi_{t} \equiv\left\{c_{t}^{i}, y_{t}^{i}, d_{t}^{i}\right\}_{i=1}^{2}, \forall t$ using a welfarist social welfare function:

$$
W_{0}=\sum_{t=0}^{\infty} \delta^{t}\left(\sum_{i=1}^{2} n_{i}\left[u\left(c_{t}^{i}\right)-z\left(y_{t}^{i} / w_{i}\right)+\beta u\left(d_{t+1}^{i}\right)\right]\right)
$$

where $\delta=(1+\eta) /(1+\rho)$ is the inter-generational discount factor, and $\rho>\eta$ is the intergenerational discount factor. We emphasize the effects of pre(un)-funding pensions on optimal policies by writing feasibility constraints as the following:

$$
\begin{aligned}
\sum_{i} n_{i} c_{t}^{i} & =\sum_{i} n_{i} y_{t}^{i}-b_{t}^{i} \\
\sum_{i} n_{i} d_{t}^{i} & =(1-\alpha)(1+\eta) b_{t}+\alpha(1+r) b_{t-1}
\end{aligned}
$$

where $b_{t}$ is the aggregate pension contributions of the generation born at $t$. By (3a) aggregate consumption of workers equals aggregate gross income minus pension contributions. By (3b) aggregate consumption of retirees depends on $\alpha \in\{0,1\}$, which captures whether public pensions are fully funded. With $\alpha=1$ consumption of current retirees is funded through their own past contributions. For simplicity, assume that these savings yield the fixed rate of return $r$, as we would find in a small open economy. With $\alpha=0$ pensions are paid with current contributions. Moreover, our modelling implicitly means that prefunding pensions ex ante shuts down all inter-generational redistribution. Although strong, this serves illustrative purposes.

It is worth noting that $\alpha$ is taken as an institutional feature that would be highly costly to reform at short notice. Although strong, this assumption captures the stylized fact that pension contribution rates are more frequently adjust than the fundamental structure of public pension funds, which requires in-depth reform. Moreover, ruling out intermediary cases $0<\alpha<1$ discards issues of convergence and allows us to directly analyze steady states, without overshadowing the intuition this paper seeks to convey. 


\section{$2.1 \quad$ Full commitment benchmark}

Choosing an optimal allocation is equivalent to designing a nonlinear tax system across workers and retirees. Suppose that at $t=0$ the social planner can once and for all promise future allocations that satisfy the feasibility constraints. He maximizes (2) by choosing $\phi_{t}, \forall t$ subject to (3a) and (3b). ${ }^{1}$ Unsurprisingly, concave utility of consumption (or aversion to inequality) gives $c_{t}^{1}=c_{t}^{2}, d_{t}^{1}=d_{t}^{2}$, and $y_{t}^{1}<y_{t}^{2} \forall t$. All individuals have identical consumptions, but type $2 \mathrm{~s}$ are invited to work more.

It is well known that such an allocation is not incentive compatible. If only gross incomes $y_{t}^{i}$ can be observed instead of types, type2 workers would mimic type1s. Second best optimality is therefore restricted to incentive compatible allocations that satisfy

$$
u\left(c_{t}^{1}\right)-z\left(y_{t}^{1} / w_{2}\right)+\beta u\left(d_{t+1}^{1}\right) \leq u\left(c_{t}^{2}\right)-z\left(y_{t}^{2} / w_{2}\right)+\beta u\left(d_{t+1}^{2}\right)
$$

Full commitment implies that the social planner commits to allocations before private information is revealed. The second best allocation satisfies $c_{t}^{1}=d_{t}^{1}<d_{t}^{2}=c_{t}^{2}$ with $y_{t}^{1}<y_{t}^{2}$. The fact that interests us the most is that consumption smoothing is preserved:

$$
\begin{cases}u^{\prime}\left(c_{t}^{i}\right) / u^{\prime}\left(d_{t+1}^{i}\right)=\beta(1+r) & \text { if } \alpha=1 \\ u^{\prime}\left(c_{t}^{i}\right) / u^{\prime}\left(d_{t}^{i}\right)=\beta(1+\rho) & \text { if } \alpha=0 .\end{cases}
$$

\subsection{Sequential governments}

Suppose now that the social planner initially promises allocations $\phi_{t}, \forall t$. Each allocation must be incentive compatible and feasible. Lagrange multipliers $\theta_{t}, \mu_{t}$, and $\lambda_{t}$ are assigned to equations (3a), (3b) and (4). However, the social planner does not have the final say. Sequential governments can later reoptimize and change allocations. We model them in the

\footnotetext{
${ }^{1}$ The first-order conditions of all Lagrangian problems are produced in the appendix.
} 
spirit of Farhi et al. (2012), where three motives induce sequential governments to renege. First, it knows retirees' types and may seek to set $d_{t}^{1}=d_{t}^{2}$. Second, they may weigh generations differently than does the initial planner. Third, accumulated assets are perceived as an inelastic tax base that can be redistributed at no immediate efficiency cost. The objective function of a time $t$ government is

$$
W_{t}=\max \pi \beta u\left(d_{t}\right)+(1-\pi) \sum_{i} n_{i}\left[u\left(c_{t}^{i}\right)-z\left(y_{t}^{i} / w_{i}\right)+\beta u\left(d_{t+1}\right)\right]
$$

where $\pi$ is the weight put on current retirees whose types are known.

Let us focus on allocations that can be promised by the planner at $t=0$ and which sequential governments will not renege on. Oftentimes, such policies have been characterized by taking the limit of the backward induction solution to a dynamic game. ${ }^{2}$ Here, young workers are conscious that their private information will be used to equalize consumption across retirees. Therefore, they reveal it only if the promised allocations maximize (6) subject to $d_{t}^{1}=d_{t}^{2}=d_{t}$, to the feasibility constraint and to the IC constraint.

To separate types, allocations must therefore allow for more inequality across workers. But what interests us is the role of accumulated assets $b_{t}$ on the outcome of this game. Denoting $\bar{\sigma}_{t}$ the allocation selected by governments (and promised by the social planner) and by $\bar{W}_{t}$ a government's value function, we find that

$$
\partial \bar{W}_{t} / \partial b_{t-1}=\alpha(1-\pi) \beta u^{\prime}\left(b_{t-1}(1+r)\right)(1+r)
$$

Thus, increasing time $t$ contributions increases next year's government's utility only if pensions are prefunded. With prefunding, current governments can decide future governments' cash-on-hand. With unfunded pensions, current governments simultaneously choose current contributions and current retirees' consumptions, when temptation to put too much weight

\footnotetext{
${ }^{2}$ For instance, see Boadway et al. (1996b,a); Boadway and Keen (1998); Brett and Weymark (2008); Debortoli and Nunes (2010); Krause and Guo (2011a,b).
} 
on the retirees is maximal.

\subsection{Sustainable contribution rules}

As shown by Chari and Kehoe (1990), a better social outcome can be sustained if households' decisions depend on history, and if history is used to "punish" governments using a triggertype strategy (the first-order conditions are provided in the appendix). History $h_{t-1}$ consists of all the allocations that have been implemented in the past. Sequential governments' strategies $\phi_{t}\left(h_{t-1}\right)$ depend on history as well.

For households' behavior, we focus on symmetric strategies (no coordination) and seek for a Perfect Bayesian Equilibrium. Sequential rationality requires that sustainable allocations are not sustained by punishment strategy that are not subgame perfect (such as households threatening never to work and consume again). The best sequence of allocations that can be sustained without commitment is such that households believe that a sequential government will not break the social planner's promises if none have been broken up until now. Whenever one government has reneged, households revert to a strategy in which they believe that governments will always be shortsighted and seek to obtain $\bar{W}_{t}\left(\alpha b_{t-1}\right)$. This is the harshest subgame perfect trigger strategy that gives us the sustainable policy that is closest to the second best.

Given this trigger strategy, sequential governments prefer the allocation promised by the social planner to re-optimizing and get $\bar{W}_{t}\left(\alpha b_{t-1}\right)$. immediately. Farhi et al. (2012) have shown that, as a consequence, the social planners' promises must satisfy a sequence of credibility constraints, which are

$$
\pi \sum_{i} n_{i} \beta u\left(d_{t}^{i}\right)+(1-\pi) \sum_{i} n_{i}\left[u\left(c_{t}^{i}\right)-z\left(y_{t}^{i} / w_{i}\right)+\beta u\left(d_{t+1}^{i}\right)\right] \geq \bar{W}_{t}\left(\alpha b_{t-1}\right), \quad \forall t .
$$

Whenever a standard second best allocation is not sustainable, (8) is binding at $t$ in the 
social planner's maximization problem. The left-hand side shows a government's welfare under the initially promised allocation. The right-hand side gives its welfare if it exploits retirees' information, and over redistributes, but where the economy reverts to the static outcome forever.

From (8) it is now apparent how sustainability requirements will modify the initial allocation. With unfunded pensions, sequential governments can yield to temptation and immediately increase resources available for retirees. Therefore, the solution is for the social planner to partially "yield to temptation" ex ante. With prefunded pensions, sequential governments can reduce contributions instead, so as to cut immediate resources to sequential governments. This is so because $\partial \bar{W}_{t+1} / \partial b_{t}>0$ if and only if $\alpha=1$. Thus, instead of giving sequential governments what they want, it can worsen the penalty suffered by the economy if any government ever reneges.

To show this clearly, let us derive the analogous contribution rules to (5) but for the best possible sustainable policy. The social planner choses $\phi_{t}, \forall t$ by maximizing (2) subject to the IC constraint (4) to which we assign Lagrange multipliers $\mu_{t}$, to the resource constraints (3a) and (3b) with multipliers $\lambda_{t}$ and $\theta_{t}$ and to the credibility constraint with multiplier $\gamma_{t}$.

For type1 individuals, contributions with unfunded pensions satisfies (the intuition is identical for type2s, as discussed in the appendix):

$$
\left(\frac{n_{1}-\mu_{t}+\gamma_{t} n_{1}(1-\pi)}{n_{1}-\mu_{t-1}+\delta \gamma_{t} \pi n_{1}+\gamma_{t-1}(1-\pi) n_{1}}\right) \frac{u^{\prime}\left(c_{t}^{1}\right)}{u^{\prime}\left(d_{t}^{1}\right)}=\beta(1+\rho)
$$

Equation (9) shows that when the credibility constraint binds every period sets $c_{t}<d_{t}$ for both types and increase contributions. This starkly contrast with the same conditions under prefunding, which is the following:

$$
\left(\frac{n_{1}-\mu_{t}+\gamma_{t} n_{1}(1-\pi)}{n_{1}-\mu_{t}+\gamma_{t+1} \delta \pi n_{1}+\gamma_{t} n_{1}(1-\pi)}\right) \frac{u^{\prime}\left(c_{t}^{1}\right)}{u^{\prime}\left(d_{t+1}^{1}\right)}=\beta(1+r)-(1-\pi) \frac{\gamma_{t+1}}{\theta_{t+1}} \beta u^{\prime}\left(\bar{d}_{t}\right) .
$$


The added term on the right-hand side captures the commitment value of prefunded pensions. By reducing aggregate contributions at $t$, the social planner reduces cash-on-hand available to the government at $t=1$. As a consequence, it reduces temptation one period ahead and makes the next period's credibility constraint less binding. Thus, we should expect that prefunding allows to sustain a policy closer to the second best.

\section{$2.4 \quad$ Numerical illustrations}

We illustrate the potential benefits of prefunding pensions using two numerical examples. We use the utility function $u(c)=c^{1-\rho} /(1-\rho)$ with $\rho=0.85$ and quadratic disutility of labor $z(y / w)=\sigma(y / w)^{2} / 2$. We fix the inter-temporal discount factor at $\delta=0.995$. A high value of $\delta$ implies that social welfare under full commitment will be similar with funded and unfunded pensions when $r=\eta$. The two illustrative scenarios are reported in table 1 .

We first study a scenario where $r=\eta=1$. If $\pi$ is low enough so the credibility constraint does not bind at the second best allocation, the funded and unfunded regimes yield a social welfare of approximately 9.6321 in the steady state. Inter generational discounting implies that retirees' consumption is marginally higher under unfunded provision.

When pensions are unfunded, increases in $\pi$ quickly translate into binding temptation. Since no commitment mechanism is available, sequential governments react by increasing retirees' consumption. Otherwise, reneging would take place later on. Social welfare decreases to eventually attain negative values.

With prefunding, a broader range of second best allocations can be sustained without commitment. Only when $\pi$ passes from 0.60 to 0.65 does the credibility constraint binding. When it does, one can readily see how pre-commitment kicks in. Instead of increasing contributions (as under unfunded pensions), the social planner reduces them to diminish sequential governments' amount of cash-on-hand that is available for redistribution. 
The second numerical example is found in the four rightmost columns of table 1 . We have set $\eta>r$ and adjusted $\rho$ so that $\delta$ remains unchanged. In our setup, $\eta>r$ makes the unfunded regime stricly dominant in any full commitment scenario. However, as $\pi$ increases the commitment value of prefunding pensions makes it preferable not to resort to pay-as-you-go schemes.

\begin{tabular}{cccccccccc}
\hline \hline \multicolumn{4}{c|}{$r=\eta=1, \delta=0.995$} & \multicolumn{3}{c}{$r=0.5, \eta=1.5, \delta=0.995$} \\
\hline \multicolumn{4}{c}{ Unfunded } & \multicolumn{3}{c}{ Prefunded } & \multicolumn{3}{c}{ Unfunded } \\
\multicolumn{1}{c}{$W_{0}$} & $b_{t}$ & $W_{0}$ & $b_{t}$ & $W_{0}$ & $b_{t}$ & $W_{0}$ & $b_{t}$ \\
\hline$\pi$ & & & & & & & & \\
0.35 & 9.6321 & 1.5244 & 9.6321 & 1.5184 & 9.7506 & 1.5742 & 9.6321 & 1.5184 \\
0.40 & 9.6282 & 1.6757 & 9.6321 & 1.5184 & 9.7466 & 1.7277 & 9.6321 & 1.5184 \\
0.45 & 9.6036 & 1.9550 & 9.6321 & 1.5184 & 9.7214 & 2.0133 & 9.6321 & 1.5184 \\
0.50 & 9.5546 & 2.2620 & 9.6321 & 1.5184 & 9.6713 & 2.3262 & 9.6321 & 1.5184 \\
0.55 & 9.4770 & 2.6023 & 9.6321 & 1.5184 & 9.5919 & 2.6725 & 9.6321 & 1.5184 \\
0.60 & 9.3634 & 2.9845 & 9.6321 & 1.5184 & 9.4754 & 3.0608 & 9.6321 & 1.5184 \\
0.65 & 9.2010 & 3.4214 & 9.6318 & 1.4824 & 9.3090 & 3.5041 & 9.6318 & 1.4829 \\
0.70 & 8.9675 & 3.9337 & 9.6306 & 1.4453 & 9.0694 & 4.0232 & 9.6306 & 1.4457 \\
0.75 & 8.6207 & 4.5561 & 9.6285 & 1.4086 & 8.7130 & 4.6539 & 9.6286 & 1.4090 \\
0.80 & 8.0576 & 5.3536 & 9.6256 & 1.3721 & 8.1480 & 5.4622 & 9.6257 & 1.3724 \\
0.90 & 4.9948 & 8.2718 & 9.6166 & 1.2967 & 4.9644 & 8.4260 & 9.6166 & 1.2969 \\
0.940 & 0.2050 & 11.1691 & 9.6110 & 1.2631 & -0.0157 & 11.3796 & 9.6111 & 1.2634 \\
0.945 & -0.9958 & 11.7659 & 9.6102 & 1.2586 & -1.2688 & 11.9901 & 9.6126 & 1.2587 \\
0.950 & -2.5048 & 12.4703 & 9.6094 & 1.2539 & -2.8460 & 12.7118 & 9.6094 & 1.2541 \\
\hline \hline
\end{tabular}

\section{Conclusion}

We used a simple model to formalize why prefunding pensions may help governments to commit. Our stylized assumptions helped us formalize why prefunding may act as a commitment device. The fundinging structure of the pension plan is taken as given, and prefunding can completely shut down the inter-generational redistribution mechanism. One must also keep in mind that prefunding provides a possibility of pre-commitment if a social planner designs the policy properly. 
More research has still to be done on this topic. Researchers, such as Blake (2000) and Barr (2002), contend that prefunding is at best an imperfect commitment device to isolate pension capital from political risks. ${ }^{3}$ While governments can (and do) break their PAYG promises, they can equally reduce the real return to pension funds, by requiring fund managers to hold government financial assets with a lower yield than they could earn elsewhere, or by withdrawing or reducing any tax privileges. The Argentinean case also convincingly demonstrates that simply ending pay-as-you-go schemes and transferring pension management to the private sector does not mechanically alleviate political risks (Kay, 2009). A new set of political risks can then emerge since prefunded assets can be perceived as an inelastic tax base by predatory and short-sighted governments, with excess redistribution and time-inconsistent policy-making as consequences.

\section{References}

Barr, Nicholas (2002) 'Reforming pensions: Myths, truths, and policy choices.' International Social Security Review 55, 3-35

Blake, David (2000) 'Does it matters what type of pension scheme you have?' Economic Journal 110, F46-F81

Boadway, Robin, and Michael Keen (1998) 'Evasion and time consistency in the taxation of capital income.' International Economic Review 39, 461-476

Boadway, Robin W., Nicolas Marceau, and Maurice Marchand (1996a) 'Investment in education and the time-inconsistency of redistributive tax policy.' Economica 63, 171-189

_ (1996b) 'Time-consistent subsidies to unlucky firms.' European Journal of Political Economy 11, 619-634

\footnotetext{
${ }^{3}$ Blake (2000) gives the example of the United Kingdom in 1997, when the Chancellor of the Exchequer removed the right of pension funds to recover the advance corporation tax paid on dividends.
} 
Brett, Craig, and John Weymark (2008) 'Optimal nonlinear taxation of income and savings without commitment.' Mimeo

Chari, V. V., and Patrick Kehoe (1990) 'Sustainable plans.' Journal of Political Economy $98,783-802$

Debortoli, Davide, and Ricardo Nunes (2010) 'Fiscal policy under loose commitment.' Journal of Economic Theory 145, 1005-1032

Diamond, Peter (1994) 'Insulation of pensions from political risk.' NBER Working Papers

_ (1996) 'Proposals to restructure social security.' Journal of Economic Perspectives 10, 6788

Farhi, Emmanuel, Christopher Sleet, Ivan Werning, and Sevin Yeltekin (2012) 'Non-linear capital taxation without commitment.' Review of Economic Studies

Kay, Stephen J. (2009) 'Political risk and pension privatization: The case of argentina (19942008).' International Social Security Review 62, 1-21

Krause, Alan, and Jan-Ting Guo (2011a) 'Dynamic income taxation without commitment: Comparing alternative tax systems.' Mimeo

Krause, Alan, and Jang-Ting Guo (2011b) 'Optimal dynamic nonlinear income taxation under loose commitment.' Mimeo

Stiglitz, Joseph E. (1982) 'Self-selection and pareto efficient taxation.' Journal of Public Economics 17, 213-240 


\section{A Supplementary material}

\section{A.1 Social planner' problems}

The Lagrangian of the social planner is

$$
\begin{aligned}
\mathcal{L} & =\sum_{t=0}^{\infty} \delta^{t}\left\{\sum_{i}\left[u\left(c_{t}^{i}\right)-z\left(y_{t}^{i} / w_{i}\right)+\beta u\left(d_{t+1}^{i}\right)\right]\right. \\
& -\lambda_{t}\left[\sum_{i} n_{i} c_{t}^{i}-\sum_{i} n_{i} y_{t}^{i}+b_{t}\right] \\
& -\theta_{t}\left[\sum_{i} n_{i} d_{t}^{i}-(1-\alpha)(1+\eta) b_{t}-\alpha(1+r) b_{t-1}\right] \\
& -\mu_{t}\left[u\left(c_{t}^{1}\right)-z\left(y_{t}^{1} / w_{2}\right)+\beta u\left(d_{t+1}^{1}\right)-u\left(c_{t}^{2}\right)+z\left(y_{t}^{2} / w_{2}\right)-\beta u\left(d_{t+1}^{2}\right)\right] \\
& \left.-\gamma_{t}\left[\widehat{W}_{t}\left(\alpha b_{t-1}\right)-\pi \sum_{i} n_{i} \beta u\left(d_{t}^{i}\right)-(1-\pi) \sum_{i} n_{i}\left[u\left(c_{t}^{i}\right)-z\left(y_{t}^{i} / w_{i}\right)+\beta u\left(d_{t+1}^{i}\right)\right]\right]\right\}
\end{aligned}
$$

Using $\partial W_{t}\left(\alpha b_{t}\right) / \partial b_{t}=\alpha(1-\pi) \beta u^{\prime}\left(\bar{d}_{t+1}\right) \alpha(1+r)$ the first-order conditions are, $\forall t$ :

$$
\begin{array}{ll}
c_{t}^{1}: \delta^{t}\left(n_{1}-\mu_{t}\right) u^{\prime}\left(c_{t}^{1}\right)-\delta^{t} n_{1} \lambda_{t}+\delta^{t} \gamma_{t} n_{1}(1-\pi) u^{\prime}\left(c_{t}^{1}\right) & =0 \\
c_{t}^{2}: \delta^{t}\left(n_{2}+\mu_{t}\right) u^{\prime}\left(c_{t}^{2}\right)-\delta^{t} n_{2} \lambda_{t}+\delta^{t} \gamma_{t} n_{2}(1-\pi) u^{\prime}\left(c_{t}^{2}\right) & =0 \\
d_{t}^{1}: \delta^{t-1}\left(n_{1}-\mu_{t-1}\right) \beta u^{\prime}\left(d_{t}^{1}\right)-\delta^{t} \theta_{t} n_{1}+\gamma_{t} \delta^{t} \pi n_{1} \beta u^{\prime}\left(d_{t}^{1}\right)+\gamma_{t-1} \delta^{t-1}(1-\pi) n_{1} \beta u^{\prime}\left(d_{t}^{1}\right) & =0 \\
d_{t}^{2}: \delta^{t-1}\left(n_{2}+\mu_{t-1}\right) \beta u^{\prime}\left(d_{t}^{1}\right)-\delta^{t} \theta_{t} n_{2}+\gamma_{t} \delta^{t} \pi n_{2} \beta u^{\prime}\left(d_{t}^{2}\right)+\gamma_{t-1} \delta^{t-1}(1-\pi) n_{1} \beta u^{\prime}\left(d_{t}^{2}\right) & =0 \\
y_{t}^{1}:-\delta^{t} n_{1} z^{\prime}\left(y_{t}^{1} / w_{1}\right) / w_{1}+\delta^{t} \mu_{t} z^{\prime}\left(y_{t}^{1} / w_{2}\right) / w_{2}+\delta^{t} n_{1} \lambda_{t}+\delta^{t} \gamma_{t}(1-\pi) z^{\prime}\left(y_{t}^{1} / w_{2}\right) / w_{2} & =0
\end{array}
$$




$$
\begin{array}{ll}
y_{t}^{2}:-\delta^{t}\left(n_{2}+\mu_{t}\right) z^{\prime}\left(y_{t}^{2} / w_{2}\right) / w_{2}+\delta^{t} n_{2} \lambda_{t}+\delta^{t} \gamma_{t}(1-\pi) z^{\prime}\left(y_{t}^{2} / w_{2}\right) / w_{2} & =0 \\
b_{t}:-\delta^{t} \lambda_{t}+\delta^{t} \theta_{t}(1-\alpha)(1+\eta)+\delta^{t+1} \theta_{t+1} \alpha(1+r)-\delta^{t+1}(1-\pi) \gamma_{t+1} \beta u^{\prime}\left(\bar{d}_{t}\right) \alpha(1+r) & =0
\end{array}
$$

In the first best we impose $\mu_{t}=0$ and $\gamma_{t}=0$. The first-order conditions reduce to. In the second best with commitment, we impose $\mu_{t}>0$ and $\gamma_{t}=0$. The conditions the give. Finally, without commitment we let $\mu_{t}>0$ and let $\gamma_{t} \geq 0$ depending on whether the second best is sustainable.

\section{Unfunded case}

Using (14a) and (14c) and simplifying for $\delta$ s gives

$$
\left(\frac{n_{1}-\mu_{t}+\gamma_{t} n_{1}(1-\pi)}{n_{1}-\mu_{t-1}+\gamma_{t-1} n_{1}(1-\pi)+\delta \gamma_{t} n_{1} \pi}\right) \frac{u^{\prime}\left(c_{t}^{1}\right)}{u^{\prime}\left(d_{t}^{1}\right)}=\frac{\beta}{\delta} \frac{\lambda_{t}}{\theta_{t}}
$$

By (14f), $\lambda_{t} / \theta_{t}=1+\eta$ and the definition of $\delta$

$$
\left(\frac{n_{1}-\mu_{t}+\gamma_{t} n_{1}(1-\pi)}{n_{1}-\mu_{t-1}+\delta \gamma_{t} \pi n_{1}+\gamma_{t-1}(1-\pi) n_{1}}\right) \frac{u^{\prime}\left(c_{t}^{1}\right)}{u^{\prime}\left(d_{t}^{1}\right)}=\beta(1+\rho)
$$

A similar operation is conducted with type 2 individuals (except that $n_{1}-\mu_{t}$ is replaced by $\left.n_{2}+\mu_{t}\right)$.

\section{$\underline{\text { Prefunded case }}$}

Again doing the analysis for type1 individuals, (14a) and (14c) gives

$$
\left(\frac{n_{1}-\mu_{t}+\gamma_{t} n_{1}(1-\pi)}{n_{1}-\mu_{t}+\gamma_{t+1} \delta \pi n_{1}+\gamma_{t} n_{1}(1-\pi)}\right) \frac{u^{\prime}\left(c_{t}^{1}\right)}{u^{\prime}\left(d_{t+1}^{1}\right)}=\frac{\beta}{\delta} \frac{\lambda_{t}}{\theta_{t+1}} .
$$


Joint with $\alpha=1$ and (14f) we get

$$
\left(\frac{n_{1}-\mu_{t}+\gamma_{t} n_{1}(1-\pi)}{n_{1}-\mu_{t}+\gamma_{t+1} \delta \pi n_{1}+\gamma_{t} n_{1}(1-\pi)}\right) \frac{u^{\prime}\left(c_{t}^{1}\right)}{u^{\prime}\left(d_{t+1}^{1}\right)}=\beta(1+r)-(1-\pi) \frac{\gamma_{t+1}}{\theta_{t+1}} \beta u^{\prime}\left(\bar{d}_{t}\right) .
$$

Again, a similar operation is conducted with type 2 individuals (except that $n_{1}-\mu_{t}$ is replaced by $\left.n_{2}+\mu_{t}\right)$.

\section{A.2 Government's problem under deviation}

The Lagrangian of a sequential government that characterizes a history independent policy) is

$$
\begin{aligned}
\overline{\mathcal{L}}_{t} & =\pi \beta u\left(d_{t}\right)+(1-\pi) \sum_{i} n_{i}\left[u\left(c_{t}^{i}\right)-z\left(y_{t}^{i} / w_{i}\right)\right]+(1-\pi) \beta u\left(d_{t+1}\right) . \\
& -\lambda_{t}\left[\sum_{i} n_{i} c_{t}^{i}-\sum_{i} n_{i} y_{t}^{i}+b_{t}\right] \\
& -\mu_{t}\left[u\left(c_{t}^{1}\right)-z\left(y_{t}^{1} / w_{2}\right)-u\left(c_{t}^{2}\right)+z\left(y_{t}^{2} / w_{2}\right)\right] .
\end{aligned}
$$

Use the fact that $d_{t+1}=\alpha b_{t}(1+r)+(1-\alpha) d_{t+1}(1+\eta)$. The government only chooses contemporaneous choice variables, which yields the following first-order conditions:

$$
\begin{array}{ll}
c_{t}^{1}:\left((1-\pi) n_{1}-\mu_{t}\right) u^{\prime}\left(c_{t}^{1}\right)-n_{1} \lambda_{t} & =0 \\
c_{t}^{2}:\left((1-\pi) n_{2}+\mu_{t}\right) u^{\prime}\left(c_{t}^{2}\right)-n_{2} \lambda_{t} & =0 \\
d_{t}: \pi \beta u^{\prime}\left(d_{t}\right)-\theta_{t} & =0 \\
y_{t}^{1}:-n_{1}(1-\pi) z^{\prime}\left(y_{t}^{1} / w_{1}\right) / w_{1}+\mu_{t} z^{\prime}\left(y_{t}^{1} / w_{2}\right) / w_{2}+n_{1} \lambda_{t} & =0 \\
y_{t}^{2}:-\left(n_{2}(1-\pi)+\mu_{t}\right) z^{\prime}\left(y_{t}^{2} / w_{2}\right) / w_{2}+n_{2} \lambda_{t} & =0 \\
b_{t}:-\lambda_{t}+(1-\alpha) \pi u^{\prime}\left(d_{t}\right)(1+\eta)+\alpha(1-\pi) u^{\prime}\left(d_{t+1}\right) & =0 .
\end{array}
$$


The ensuing value function $\bar{W}_{t}\left(\alpha b_{t-1}\right)$ satisfies $\partial \bar{W}_{t} / \partial b_{t-1}=(1-\pi) \alpha \beta u^{\prime}\left(b_{t-1}\right)$, which is positive if and only if $\alpha=1$, since $b_{t-1}$ has been chosen last period. 